\title{
627 Ultrasonic welding of ceramics and metals
}

\author{
Hisashi Imai*, Shin-ichi Matsuoka* \\ *Department of Mechanical System Engineering, Toyama Prefecturel University \\ 5180, Kurokawa, Kosugimati, Imizugun, Toyama, 939-0398, Japan
}

\begin{abstract}
This paper describes an experimental study of the ultrasonic welding of ceramics and metals, using inserts. Ultrasonic welding has made possible the welding of various ceramics, such as $\mathrm{Al}_{2} \mathrm{O}_{3}, \mathrm{SiO}_{2}, \mathrm{ZrO}_{2}$, and $\mathrm{Si}_{3} \mathrm{~N}_{4}$, to various metals at room temperature, both quickly and easily when compared to other welding methods. Ultrasonic welding can be carried out in many different ways, such as the direct welding of ceramics and metals in the coating of metals or to a ceramics surface by vacuum deposition, and in applications involving the insertion of activated metals. When cleaned with forced ultrasonic vibration the contact surfaces need no further surface treatment. The insert material and the vaporized film used for auxiliary purposes act as binders to facilitate welding, but there is little difference in welding strength between welds with a metal insert and those with a vaporized film. Moreover, the material can be processed easily, the operation produces little heat, and there is virtually no resultant weakness in the product.
\end{abstract}

Key Words : Ultrasonic welding, Ceramics, insert, Vaporized film

\section{Introduction}

Ceramics have good chemical and physical properties of high stability and heat resistance, high intensity, corrosion resistance, and electric insulation. Bonding ceramics to metal has many important uses in industries such as in electronic component manufacturing. However, the many factors that influence strength and reliability must be considered for both junctions. The forming factors are also important. (1) The chemical reactivity between materials, (2) The crystallographic relation in the interface, (3) The thermal stress which originates from the thermal expansion difference (residual stress), (4) The adhesion of the interface, (5) The junction plane grinding condition, and (6) The compatibility with the environment.

Generally, solid phase bonding is used to bond different materials. There are many types of this method. Such as friction joints, explosive welding, ultrasonic welding and diffusion bonding. Ultrasonic welding, considered in this study, can be used to easily to join together materials in any environment in a short time, and can be also applied to any ceramics. However, there are few reports on this method, and problems in the bonding condition and junction process remain.

\section{Experimental method and experimental condition}

A diagram of the junction and ultrasonic welding machine is shown in Figure 1. In experiments where an insert of junction support material is used, the figure illustrates its placement in the trial. Either metal foil or vacuum deposited film were used when an insert of junction material was tested. The material used for the junction is shown in Table1. The ceramics were ordinary-temperature sintered compact, and the surface roughness was polished to about $1(\mu \mathrm{m})$.

The bonding condition is shown in Table 2.

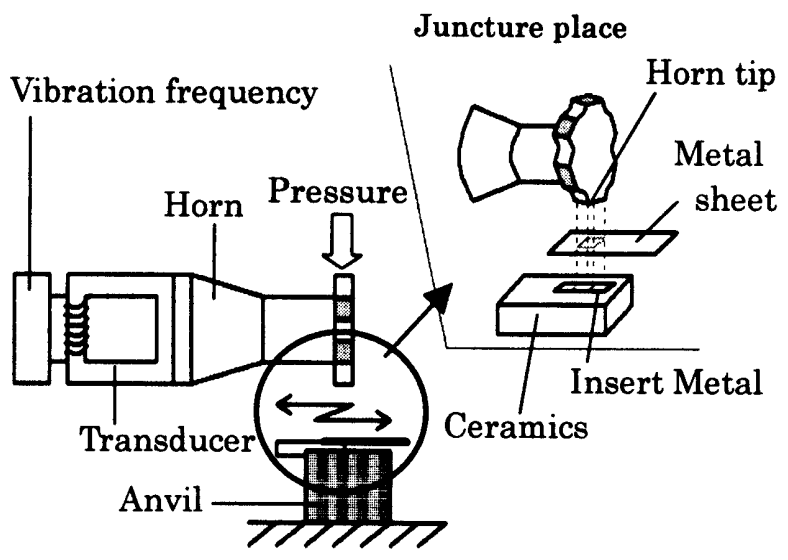

Fig.1 Outline of juncture place and ultrasonic welding machine 
Table 1 Material for the junction

(a) Metal sheet

\begin{tabular}{|c|c|c|}
\hline- & Size $(\mathrm{mm})$ & Composition $(\%)$ \\
\hline $\mathrm{Al}$ & $50(30) \mathrm{L} \times 5 \mathrm{~W} \times 0.01-0.3 \mathrm{~T}$ & $99.5-99.999$ \\
\hline $\mathrm{Cu}$ & $50 \mathrm{~L} \times 5 \mathrm{~W} \times 0.02 \cdot 0.5 \mathrm{~T}$ & $99.9-99.97$ \\
\hline $\mathrm{Zn}$ & $50 \mathrm{~L} \times 5 \mathrm{~W} \times 0.2-0.3 \mathrm{~T}$ & 99.99 \\
\hline $\mathrm{Ni}$ & $50(30) \mathrm{L} \times 5 \mathrm{~W} \times 0.05-0.2 \mathrm{~T}$ & $99.7-99.97$ \\
\hline $\mathrm{Ti}$ & $50(30) \mathrm{L} \times 5 \mathrm{~W} \times 0.005 \cdot 0.2 \mathrm{~T}$ & $99.5-99.6$ \\
\hline $\mathrm{Nb}$ & $50(30) \mathrm{L} \times 5 \mathrm{~W} \times 0.05-0.2 \mathrm{~T}$ & 99.9 \\
\hline $\mathrm{Zr}$ & $50 \mathrm{~L} \times 5 \mathrm{~W} \times 0.2 \mathrm{~T}$ & 99.8 \\
\hline $\mathrm{Mo}$ & $50(30) \mathrm{L} \times 5 \mathrm{~W} \times 0.05-0.2 \mathrm{~T}$ & 99.95 \\
\hline
\end{tabular}

※ ( ): it was used as an insert material.

(b) Ceramics (atmospheric sintered body)

\begin{tabular}{|c|c|}
\hline & Size $(\mathrm{mm})$ \\
\hline $\mathrm{ZrO}_{2}, \mathrm{Si}_{3} \mathrm{~N}_{4}, \mathrm{SiC}$ & $50 \mathrm{~L} \times 5 \mathrm{~W} \times 3 \mathrm{H}$ \\
\hline
\end{tabular}

Table 2 Bonding condition

\begin{tabular}{|c|c|}
\hline Output & $600 \mathrm{~W}(19 \mathrm{kH})$ \\
\hline Amplitude of the ultrasonic vibration & $30(\mu \mathrm{m})$ \\
\hline For the impression hour & $0 \cdot 2.5(\mathrm{~s})$ \\
\hline Junction pressure & $0 \cdot 13(\mathrm{MPa})$ \\
\hline The ordinary temperature & - \\
\hline
\end{tabular}

Using the bonding material, the following were done: Comparison of bond strength by shear tensile test, SEM observation of bonded interface and EDX analysis of component. The pressurization area of the horn chip was $4 \times 4\left(\mathrm{~mm}^{2}\right)$, and this was made to be the nominal junction area. Bond strength (o) is the value obtained by dividing the largest shear tensile strength by the nominal junction area.

\section{Experiment result and consideration}

3.1 Possibility of material junction in various combinations

Ultrasonic welding was tried using various ceramics and metallic materials, and the bondability was investigated. For the metallic materials the following conditions that are considered were assumed to affect the junction between ceramics and metal.

(1) Good wettability for ceramics.

(2) Soft material.

(3) Low melting metal.

(4) Active metal.

The experimental results are shown in Tables

3. Table 3(a) shows the junction possibility in joining the material directly together. Table $3(\mathrm{~b})$ shows the junction possibility between metals and ceramics using $\mathrm{Cu}$ as insert material. Table 3(c) shows the junction possibility when using vacuum deposited film as insert material in the junction between ceramics and $\mathrm{Cu}$ in ceramics. In the figure, the symbols show the following.

(0) : The junction is possible, and the junction strength is high.

$\mathrm{O}$ : The junction is possible, but the junction strength is low.

$\triangle:$ The junction is impossible, but transfer of the metallic material can be confirmed.

- : Junction is impossible.

Table 3 Possibility of the material junction in various combinations

(a) Direct junction

\begin{tabular}{|c|c|c|c|c|c|c|c|c|}
\hline & $\mathrm{Al}$ & $\mathrm{Cu}$ & $\mathrm{Zn}$ & $\mathrm{Ni}$ & $\mathrm{Ti}$ & $\mathrm{Nb}$ & $\mathrm{Zr}$ & $\mathrm{Mo}$ \\
\hline $\mathrm{ZrO}_{2}$ & $\bigcirc$ & $\bigcirc$ & $\bigcirc$ & - & - & - & $\bigcirc$ & $\triangle$ \\
\hline $\mathrm{Si}_{3} \mathrm{~N}_{4}$ & $\bigcirc$ & - & - & - & - & - & $\bigcirc$ & - \\
\hline $\mathrm{SiC}$ & $\bigcirc$ & - & - & - & - & - & $\bigcirc$ & - \\
\hline
\end{tabular}

(b) Using insert material (metal foil, thin plate)

\begin{tabular}{|c|c|c|c|c|c|c|}
\hline & $\mathrm{Al}$ & $\mathrm{Zn}$ & $\mathrm{Ni}$ & $\mathrm{Ti}$ & $\mathrm{Nb}$ & $\mathrm{Mo}$ \\
\hline $\mathrm{ZrO}_{2}$ & $\bigcirc$ & $\bigcirc$ & - & $\bigcirc$ & $\bigcirc$ & $\triangle$ \\
\hline $\mathrm{Si}_{3} \mathrm{~N}_{4}$ & $\bigcirc$ & - & - & $\bigcirc$ & - & - \\
\hline $\mathrm{SiC}$ & $\bigcirc$ & - & - & $\bigcirc$ & - & - \\
\hline
\end{tabular}

(c) Using insert material (The vacuum deposited film)

\begin{tabular}{|c|c|c|}
\hline & $\mathrm{Al}$ & $\mathrm{Cu}$ \\
\hline $\mathrm{ZrO}_{2}$ & $\triangle$ & $\triangle$ \\
\hline $\mathrm{Si}_{3} \mathrm{~N}_{4}$ & $\triangle$ & $\triangle$ \\
\hline
\end{tabular}

The experiment results showed that $\mathrm{Al}$ had very good bondability for ceramics, and it was possible to get a firm bonding material compared to other metallic materials. This is thought to be because $\mathrm{Al}$ has good wettability, is a soft material, and has a low melting point.

Although thin plate metal foil $\mathrm{Al}$ had the highest rank in this experiment, vacuum deposited film of $\mathrm{Al}$ was not as successful.

This may have been due to the insufficient amount of $\mathrm{Al}$ deposited at only $1.0(\mu \mathrm{m})$. 
3.2 Relationship between bond strength and bonding conditions

Figure 2 shows the result of investigating the junction possibility of each bonding material, $\mathrm{ZrO}_{2} / \mathrm{Al} / \mathrm{Cu}, \mathrm{Si}_{3} \mathrm{~N}_{4} / \mathrm{Al} / \mathrm{Cu}$, and $\mathrm{SiC} / \mathrm{Al} / \mathrm{Cu}$ when aluminum foil was used as insert material. The figure shows that the junction is possible even for the combination of junction pressure $(\mathrm{Pc})$ ranging from 1.5 to $13(\mathrm{MPa})$ and ultrasonic vibration time $(\mathrm{t})$ ranging from 0.5 to $2.5(\mathrm{~s})$. The ultrasonic wave time necessary to form the junction can be shortened by increasing the junction pressure.

However, when excessive junction pressure is applied or when the time is too long, ultrasonic vibration has no effect and a well bonded material is not obtained.

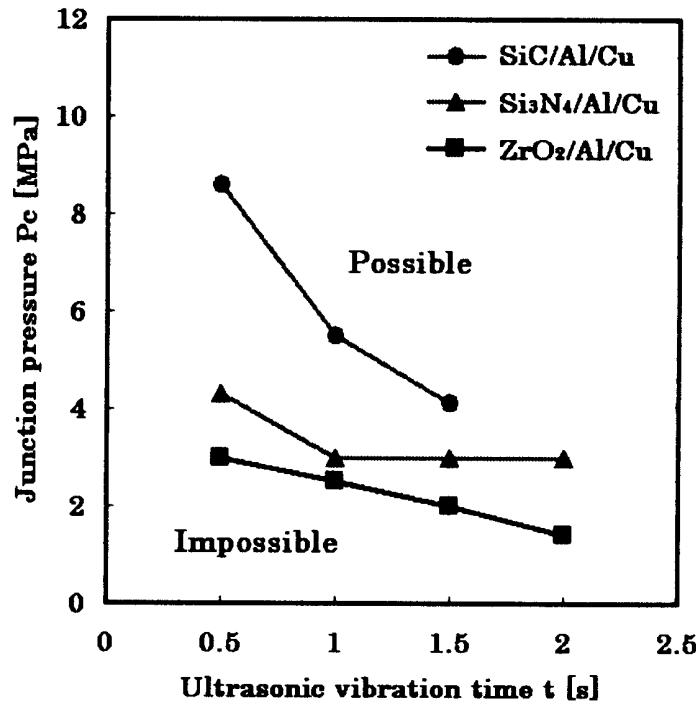

Fig.2 Region of which the junction is possible

Next, the effect of the bonding condition on bond strength (ow) was investigated. Figure 3 shows the relationship between ultrasonic vibration time $(\mathrm{t})$ and bond strength (ow), and junction pressure $(\mathrm{Pc})$ and bond strength (ow) for the Si3N4/Al/Cu bonding material. The bond strength increased with time and junction pressure in any combination. The effect of the junction pressure on the bond strength is greater than that of time. The temperature of the bonded interface rises as the junction pressure and time increase due to the friction heat, and the materials show agglutination. This seems to be created an increase in the bond strength.

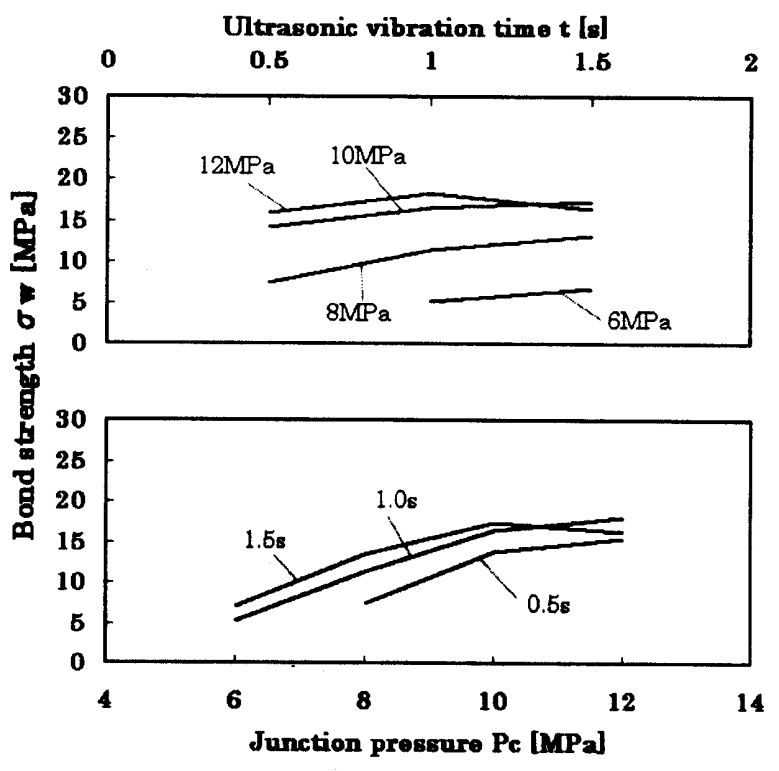

Fig.3 Relationship between ultrasonic vibration time $(\mathrm{t})$ and bond strength (ow) and junction pressure $(\mathrm{Pc})$ and bond strength (ow) in the Si3N4/Al/Cu bonding material

$\left(\mathrm{Si}_{3} \mathrm{~N}_{4}, \mathrm{Al}: 0.1(\mathrm{~mm}), \mathrm{Cu}: 0.17(\mathrm{~mm})\right)$

Figure 4 shows as graph of the temperature at the bonded interface of each bonding material. For a fixed time of $1 \mathrm{~s}$ the temperature of both bonding material increases with the increase in the junction pressure For example, the temperature reaches about $440\left({ }^{\circ} \mathrm{C}\right)$ in the $\mathrm{ZrO}_{2} / \mathrm{Al} / \mathrm{Cu}$ bonding material. Under this situation, diffusion of the interatomic in the bonded interface is expected.

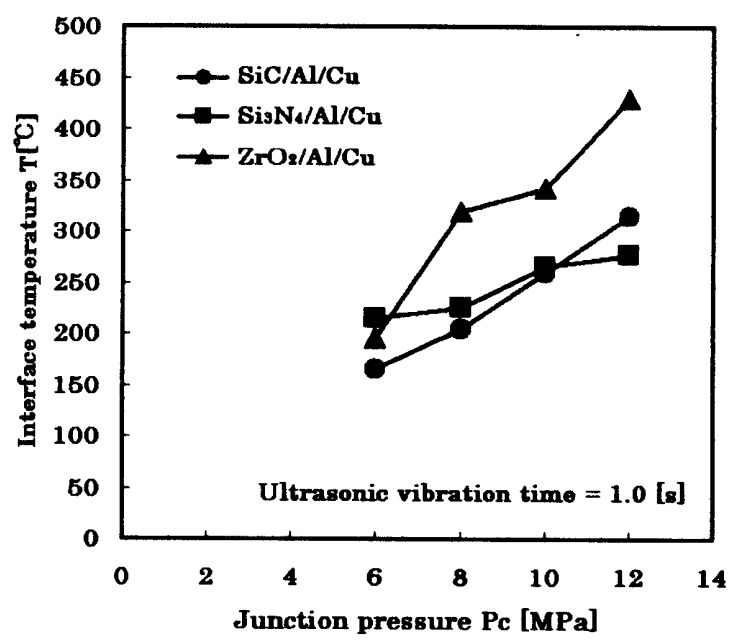

Fig.4 Relationship between bonded interface temperature and junction pressure 


\subsection{Properties of the bonded interface}

SEM photographs and EDX linear analysis of the bonded interface of the $\mathrm{ZrO}_{2} / \mathrm{Al} / \mathrm{Cu}$ bonding material are shown in Figure 5 . It can be seen that the bonded interface has no junction defects of peeling on voids. It is considered that $\mathrm{Al}$ is an effective insert material and that a good junction is formed as a whole. A transition layer of about $1(\mu \mathrm{m})$ is confirmed at the bonded interface by EDX linear analysis. This a reaction layer and diffusion layer seem to have been formed.

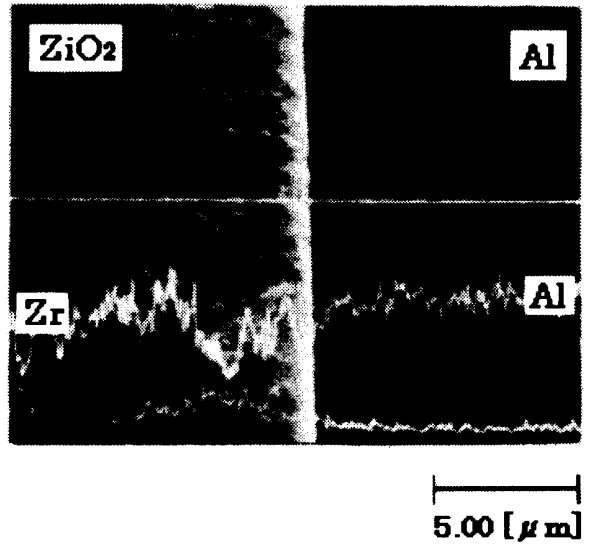

Fig.5 EDX linear analysis result of the bonded interface of bonding material $\mathrm{ZrO}_{2} / \mathrm{Al} / \mathrm{Cu}$

4. Consideration of process and mechanism of ultrasonic welding

Ultrasonic welding involves synergistic effects of various elements from the junction start to the end. The process and mechanism of ultrasonic welding is examined below based on the results of this study.

The process of junction formation can be divided into three; 1) initial stage, 2) metaphase, and 3) final stage.

1) Initial stage

In the junction surface, oxide film and organic coating are destroyed and scattered by applying ultrasonic vibration, (Fig.6 (b)). Oxide film and organic coating is removed as vibration is applied. (Fig.6 (c)), Therefore, impurities are not adsorbed, and the materials adheres.

2) Metaphase

Friction heat is generated at the bonded interface by the vibration. Plasticity deformability of the metallic material increases by this friction heat, coursing an adhesion of the materials increases (Fig.6 (d)), therefore, the contact area of the materials increases.

\section{3) Final stage}

It was proven that the temperature rise by friction heat caused diffusion of atoms at the junction surface. There is a temperature rise, and a diffusion layer is formed.

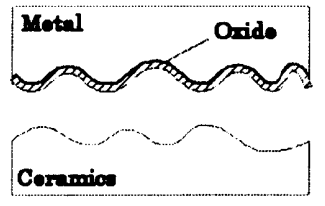

(W) Bofore the junotion

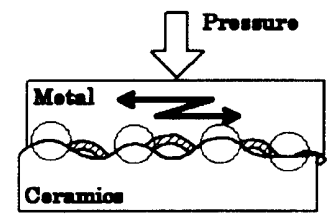

6) The imprescion of tho ultranonio vibretion (2)

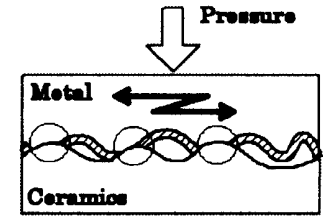

(b) Tho impreccion of the vltragonio vibretion (1)

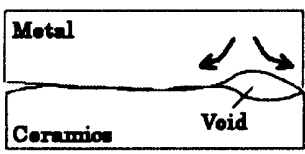

(d) The plantio flow by the preararisation
Fig.6 The behavior of bonded interface in the ultrasonic welding

\section{Conclusion}

The junction possibility between various materials and the effect and characteristics of ultrasonic welding were examined. It was shown that it is possible to achieve a firm bond by using $\mathrm{Al}$ in ultrasonic welding.

The bond strength increases as the junction pressure and application time increase, and the magnitude of the junction pressure have a greater effect on the bond strength than time.

EDX linear analysis and SEM observation confirmed that the bonded interface formed a good plane without peeling, and a transition layer of about $1(\mu \mathrm{m})$ was confirmed. The formation of a reaction layer and diffusion layer is this expected.

The application of heated junction by ultrasonic vibration energy to other metals is now being considered.

\section{Reference}

[1] The patent in Japan, No.1607227, (1991)

[2] Shinya Iwamoto, Munemiya Sigeyuki, The Junction Of Metal And Ceramics (Japanese), (1990), p1 [3] Sin-ichi Matsuoka, JSME Journal Series C, (1989),p55-517 